\title{
Expression of ENaC, SGK1 and Nedd4 isoforms in the cochlea of guinea pig
}

\author{
Shi-Xun Zhong', Guo-Hua Hu', Zhao-Hua Liu \\ ${ }^{1}$ Department of Otolaryngology, The First Affiliated Hospital, Chongqing Medical University \\ ${ }^{2}$ Department of Otolaryngology-Head and Neck Surgery, Daping Hospital, The Third Military \\ Medical University, Chongqing, P.R. China
}

\begin{abstract}
It has been demonstrated that the epithelial sodium channel ( $\mathrm{ENaC})$ may play critical roles in (re) absorbing $\mathrm{Na}^{+}$from apical plasma membrane in various tissues and cells. Moreover, the serum glucocorticoid-inducible kinase 1 (SGK1) and the ubiquitin-protein ligase neural precursor cell-expressed, developmentally downregulated isoforms Nedd4 are involved in $\mathrm{ENaC}$ regulation in response to hormones such as aldosterone, vasopressin and insulin. The aim of the study was to investigate the cellular localizations of ENaC subunits, SGK1, and Nedd4 isoforms in the cochlea of guinea pig. Ten adult guinea pigs were sacrificed and their cochleas were collected. The expression patterns of ENaC subunits, SGK1 and Nedd4-2 isoforms in the guinea pig cochlea were studied by immunohistochemistry with the specific polyclonal rabbit antibodies against rat $\alpha-, \beta$ - and $\gamma$-ENaC, SGK1, Nedd4-1/2 and Nedd4-2. The results showed that all these proteins were extensively expressed in various regions of the cochlea. They were found in the spiral ligament, organ of Corti, spiral limbus, spiral ganglion and Reissner's membrane with different staining patterns. The results indicated that a $\mathrm{Na}^{+}$transport system may exist in the cochlea of guinea pig consisting of ENaC, SGK1 and Nedd4, which may work in concert to transport $\mathrm{Na}^{+}$and to maintain homeostasis in inner ear as it does in other epithelia. (Folia Histochemica et Cytobiologica 2014, Vol. 52, No. 2, 144-148)
\end{abstract}

Key words: guinea pig; cochlea; ENaC; SGK1; Nedd4 isoforms; immunohistochemistry

\section{Introduction}

The endolymph in membranous labyrinth is characterized by rich potassium and poor sodium content. It has been reported that the $\mathrm{K}^{+}$concentration is $160 \mathrm{mM}$ and $\mathrm{Na}^{+}$concentration is $1.5 \mathrm{mM}$ in the cochlear endolymph while they are $150 \mathrm{mM}$ and 9 $\mathrm{mM}$ respectively in the vestibular endolymph [1]. The disequilibrium of potassium and sodium metabolism may interfere with the function of the sensory hair cells in cochlea and vestibule, and with generation of endocochlear potential (EP) [2, 3]. Hypoabsorption of $\mathrm{Na}^{+}$from vestibular lumen has been suggested to

Correspondence address: S.-X. Zhong,

Department of Otolaryngology, The First Affiliated Hospital

Chongqing Medical University,

No.1, Youyi Road, Yuzhong District,

Chongqing 400016, P.R. China;

tel.: +8623 89012981; fax: +862368811487

e-mail: zhongsx@sohu.com be associated with endolymphatic hydrops, the pathological base of Meniere's disease [4].

Multiple reports have shown that $\mathrm{Na}^{+} \mathrm{K}^{+}$-ATPase and $\mathrm{Na}-\mathrm{K}-\mathrm{Cl}$ cotransporter are the most important molecules involved in $\mathrm{K}^{+}$transport in the inner ear. They are expressed in cochlea, vestibule and endolymphatic sac with special patterns in various species and in different development stages [5, 6]. However, the mechanism underlying sodium transport in inner ear remains incompletely understood to date.

Epithelial sodium channel $(\mathrm{ENaC})$ is a member of the degenerin/ENaC gene superfamily. It has been shown that $\mathrm{ENaC}$ may play critical roles in (re)absorbing $\mathrm{Na}^{+}$by apical plasma membrane in variant tissues and organs such as kidney, colon and lung, and that it is regulated by serum- and glucocorticoid-inducible kinase 1 (SGK1) and the ubiquitin-protein ligase neural precursor cell-expressed, developmentally downregulated isoforms Nedd4 [7]. We have reported the expression patterns of $\mathrm{ENaC}$, SGK1 and Nedd 4 isoforms in the rat inner ear by immunohistochemistry $[8,9]$. 
Couloigner et al. [10] and Grunder et al. [11] have demonstrated the presence of $\mathrm{ENaC}$ subunits in rat inner ear by in situ hybridization. The present study describes for the first time the distribution of $\mathrm{ENaC}$ subunits, SGK1 and Nedd4 isoforms in the cochlea of adult guinea pig by immunohistochemistry.

\section{Material and methods}

Animals and tissue preparation. The procedures concerning animals reported in this study were approved by the Animal Care and Use Committee of the Chongqing Medical University. Ten adult guinea pigs weighing 300-500 g were used. After the animal was anesthetized intraperitoneally with pentobarbital sodium $(40 \mathrm{mg} / \mathrm{kg}$ body weight), the thoracic cavity was opened, and the abdominal aorta was clamped. The upper body was perfused via cardiac puncture with $200 \mathrm{~mL}$ of $0.9 \%$ saline, followed by $4 \%$ paraformaldehyde at $\mathrm{pH} 7.3$ till the neck became stiff. Following decapitation, the temporal bone was removed rapidly and the cochlea was dissected carefully. The cochlear compartment was perilymphatically perfused with $4 \%$ paraformaldehyde after the oval and round windows were opened and a small hole was made in the otic capsule at the cochlear apex. The cochlea was placed in the same fixative overnight at $4^{\circ} \mathrm{C}$. The specimens which had been decalcified in 10\% EDTA for 10-20 days were embedded in paraffin using routine procedures. Tissues were sectioned with a rotary microtome at $6 \mu \mathrm{m}$ and mounted on poly-L-lysine-treated (Beijing Zhongshan Biotechnology Co. Ltd., Beijing, China) glass slides.

Immunohistochemistry. Immunohistochemistry was performed according to the method previously reported with minor modification [12, 13]. Briefly, tissues were deparaffinized $10 \mathrm{~min}$ in xylene and rehydrated in decreasing alcohol concentrations. Endogenous peroxidase was blocked by $1.5 \%$ $\mathrm{H}_{2} \mathrm{O}_{2}$ in absolute methanol for $10 \mathrm{~min}$. After being washed three times in phosphate-buffered saline (PBS), sections were equilibrated with $5 \%$ goat serum for $10 \mathrm{~min}$ at room temperature to block nonspecific binding sites. Slides were incubated overnight at $4^{\circ} \mathrm{C}$ with the primary antibodies. Polyclonal rabbit antibodies against $\alpha$-, $\beta$-, or $\gamma$-subunits of ENaC (diluted 1:200 in PBS, generous gifts from Prof. Pascal Barbry, Institut de Pharmacologie Moléculaire et Cellulaire, University of Nice Sophia Antipolis, Sophia Antipolis, France), antibodies against SGK1 (diluted 1:400, generous gift from Prof. Nicola Perrotti, Universita di Catanzaro, Catanzaro, Italy), Nedd4-1/2 (this antibody reacts with both Nedd4-1 and Nedd4-2) and Nedd4-2 (specific for Nedd4-2) (diluted 1:400 respectively, generous gifts from Prof. Olivier Staub, University of Lausanne, Lausanne, Switzerland) were raised in rabbit. These antibodies have been described previously [14-16]. Following the primary incubation step, slides were washed three times for $10 \mathrm{~min}$ in PBS. Next, sections were incubated for $30 \mathrm{~min}$ at room temperature with biotin-labelled goat anti-rabbit IgG (Beijing Zhongshan Biotechnology Co. Ltd., Beijing, China), rinsed three times in PBS (5 min each), and incubated with streptavidin-conjugated peroxidase (Beijing Zhongshan Biotechnology) for $30 \mathrm{~min}$ at room temperature, washed thereafter with PBS and counterstained with hematoxylin. Following being washed in PBS three times, sites of bound primary antibodies were visualized by monitoring their development in diaminobenzidine substrate medium (DAB, Beijing Zhongshan Biotechnology). Sections were examined under an Olympus microscope (Olympus, Osaka, Japan), and TCFY-2050 (Yuancheng, Beijing, China) pathology system was used for the acquisition of images. Ten visual field images were randomly collected from every section. Cell with buffy stain in cytoplasm or membrane was considered to be positive for each antibody. Image-Pro plus 5.0 software (Media Cybemetrics, Rockville, MO, USA) was used to calculate the mean optical density (OD) of each vision field to assess the immunopositivity of the images.

In the positive control experiments, kidney tissue was incubated with the same primary antibodies since the expressions of ENaC, SGK1 and Nedd4 in kidney have been well demonstrated [16-18]. In the negative control experiments, sections were processed along the same protocol except that the primary antibodies were replaced by normal rabbit serum (Beijing Zhongshan Biotechnology).

\section{Results}

Our results showed that all three subunits of $\mathrm{ENaC}$, $\alpha$-, $\beta$ - and $\gamma$-, were widely distributed in the cochlea with different staining patterns (Figure 1A-C). Strong immunoreactivity of $\alpha-\mathrm{ENaC}$ was found in the spiral limbus, and to a less extent, in the spiral ligament and organ of Corti. No immunoreactivity was found in the spiral ganglion. Beta-ENaC staining was observed in the spiral ligament, spiral limbus, organ of Corti and spiral ganglion. Prominent immunolabeling of $\gamma-\mathrm{ENaC}$ was seen in the superior part of the spiral ligament, spiral limbus, organ of Corti and spiral ganglion. The Reissner's membrane was labeled by all three antibodies. No expression of $\alpha-, \beta-$, or $\gamma$-ENaC was detected in the stria vascularis.

Immunopositive labelings of SGK1, Nedd4-1/2 and Nedd4-2 were found extensively in the cochlea with similar patterns as $\mathrm{ENaC}$, including the spiral ligament, spiral limbus, organ of Corti, Reissner's membrane and spiral ganglion. None of them was detected in the stria vascularis (Figure 1D-F). Figure 2 shows the histogram of the OD values of immunopositive cells for every antibody in various areas of guinea pig cochlea.

In the positive control experiments, the immunoreactivities of all these proteins were located in the cells lining the collecting ducts. In the negative controls no 

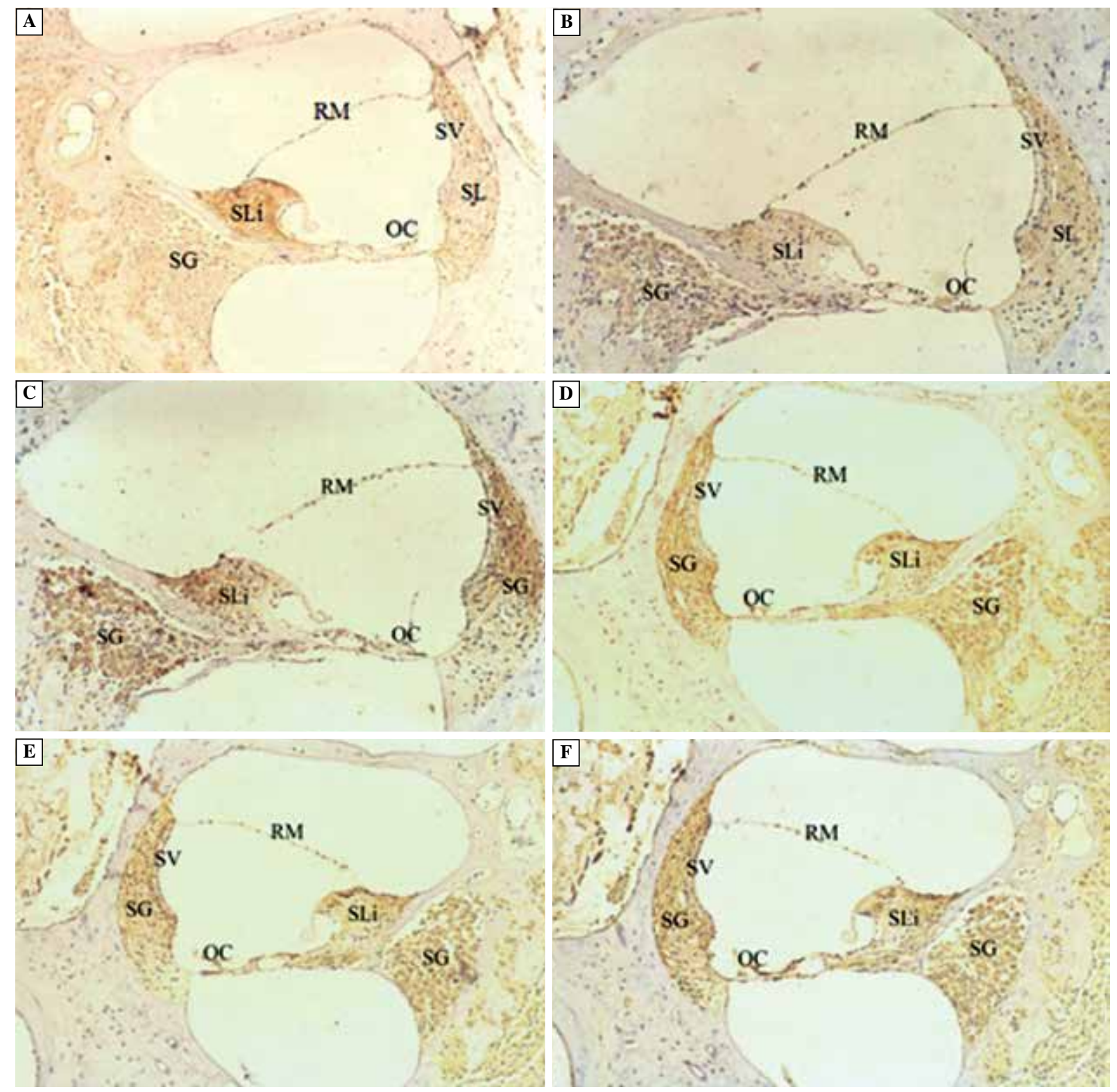

Figure 1. Immunolocalization of ENaC subunits, SGK1 and Nedd4-2 isoforms in the guinea pig cochlea. A. Strong immunoreactivity of $\alpha$-ENaC was found in the spiral limbus, and to a less extent, in the organ of Corti and spiral ligament. No immunoreactivity was present in the spiral ganglion. B. Beta-ENaC staining was observed in the spiral ligament, spiral limbus, organ of Corti and spiral ganglion. C. Significant immunolabeling of $\gamma$-ENaC is seen in the superior part of spiral ligament, spiral limbus, organ of Corti and spiral ganglion. D, E and F. Immunopositive reactions for SGK1, Nedd4-1/2, and Nedd4-2, respectively, were detected in the spiral ligament, spiral limbus, organ of Corti and spiral ganglion in similar patterns. The Reissner's membrane was labeled by all used antibodies, while the stria vascularis was not labeled by any of them. Abbreviations: OC, organ of Corti; RM, Reissner's membrane; SL, spiral ligament; SLi, spiral limbus; SG, spiral ganglion; SV, stria vascularis. Magnifications: A × 100; B-F × 200

staining by any antibody could be detected in any area (data not shown).

\section{Discussion}

To the best of our knowledge, the present study is the first demonstration of the expression and cellular distribution of ENaC subunits, SGK1, and Nedd4 isoforms proteins in the cochlea of guinea pig. Our results identified differential expression patterns of these proteins in different regions of the cochlea. They were extensively distributed in the cochlea including the spiral ligament, organ of Corti, Reissner's membrane, spiral limbus, and spiral ganglion except for $\alpha$-ENaC. 


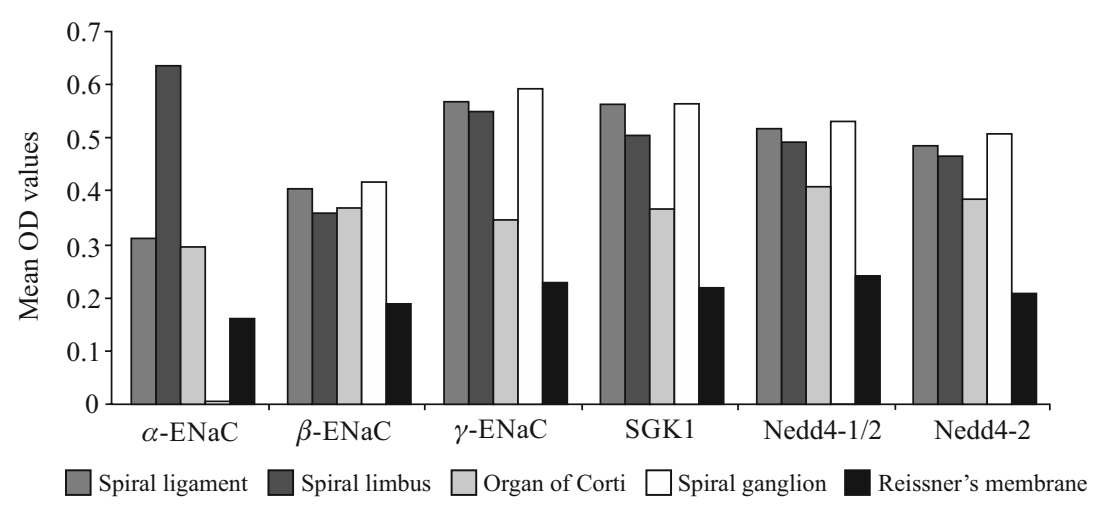

Figure 2. The histogram presents the mean OD values of immunopositive cells for every antibody in various areas of cochlea

Most of these regions are closely related to the regulation of endolymph production and resorption.

We have reported the expression of $\mathrm{ENaC}$ subunits, SGK1 and Nedd4 isoforms proteins in the rat cochlea $[8,9]$. The most significant difference between guinea pig and rat is that in guinea pig no immunoreactivity of any protein was found in the stria vascularis and no $\alpha$-ENaC was detected in the spiral ganglion. It indicates that a species difference may exist in expression patterns of these proteins in cochlea between guinea pig and rat.

$\mathrm{ENaC}$ channels are heteromultimeric proteins formed by the association of three homologous subunits, $\alpha, \beta$, and, $\gamma$, with a stoichiometry of $\alpha_{2} \beta \gamma$ or $\alpha_{3} \beta_{3} \gamma_{3}[19]$. Each subunit contains two transmembrane domains, an extracellular loop and intracellular $\mathrm{N}$ - and C-termini. Our data in combination with previous reports by Couloigner et al. [10] and Grunder et al. [11] show that all three subunits of ENaC could be detected in cochlea. This pattern may be of great importance for $\mathrm{ENaC}$ to form functional channel. It has been demonstrated that a subunit alone can generate channels, but $\beta$ or $\gamma$ subunits cannot form functional channels by themselves. Nonetheless, they impart specific properties to the heterooligomeric complex, e.g. to help transport sodium or to stabilize the $\alpha$ subunit in the cell membrane. In addition, $\alpha$ subunit in combination with either $\beta$ or $\gamma$ ones forms channels with distinct affinities for their blocker amiloride, with distinct single channel kinetics and ion selectivity, indicating that different combinations of subunits allow functional diversity [20]. It has been demonstrated that dominant gain-of-function mutations of $\mathrm{ENaC}$ gene cause Liddle's syndrome, an inherited form of hypertension, and conversely, loss-of-function mutations cause pseudohypoaldosteronism type 1 , characterized by salt wasting and hypotension [21].

Furthermore, an ENaC-like subunit, $\delta$-subunit, has been identified in human brain, pancreas, testis, and ovary, with biophysical properties distinct from those of the epithelial $\mathrm{Na}^{+}$channel. It has been found that $\delta$-subunit is able to replace $\alpha \mathrm{ENaC}$ in forming functional $\mathrm{Na}^{+}$channels [22].

Nedd4, including two isoforms, Nedd4-1 and Nedd4-2, is an ubiquitin protein ligase that works in ubiquitination of plasma membrane proteins. SGK, including three isoforms, SGK1, SGK2 and SGK3, is a member of the 'AGC' family of protein kinases. Kamynina et al. proposed the following model in an attempt to elucidate the mechanism underlying $\mathrm{Na}^{+}$ transport by hormone [7]. Aldosterone, on biding to its receptors and translocation into the nucleus, induces the expression of SGK1. PY motif of SGK1 will bind to a WW domain of Nedd4-2 and phosphorylate it. The weakened interaction between $\mathrm{ENaC}$ and Nedd4-2 due to phosphorylation of Nedd4-2 results in the accumulation of $\mathrm{ENaC}$ at the cell surface because of decreased endocytosis and degradation, and sequentially increases $\mathrm{Na}^{+}$reabsorption [7].

The large electrochemical gradient for $\mathrm{Na}^{+}$existing across the apical cell membrane provides the driving force for the entry of $\mathrm{Na}^{+}$into the cell. Active $\mathrm{Na}^{+}$transport across the basolateral membrane is accomplished by $\mathrm{Na}^{+}, \mathrm{K}^{+}$-ATPase. $\mathrm{Na}^{+}, \mathrm{K}^{+}$-ATPase presence has also been demonstrated in inner ear of various species with differential expression patterns. Taking into account these studies and our reports, it seems reasonable to consider that $\mathrm{ENaC}$, SGK1, Nedd4-2, and $\mathrm{Na}^{+}, \mathrm{K}^{+}$-ATPase may be the key molecules responsible for sodium and potassium exchange in inner ear. In addition, other molecules responsible for endolymph transport such as $\mathrm{Na}-\mathrm{K}-\mathrm{Cl}$ cotransporter, $\mathrm{Na} / \mathrm{H}$ exchanger have also been found. We deduce that these proteins may work together to maintain endolymph homeostasis in the inner ear.

To our surprise, no ENaC subunits, SGK1 or Nedd4 isoform proteins were found in the stria vascularis of guinea pig. It is a significant difference between guinea 
pig and rat. The stria vascularis is believed to play critical roles in regulating endolymph homeostasis and generating EP. Wangemann [23] proposed that potassium is pumped into the marginal cells by basolateral $\mathrm{Na}^{+}, \mathrm{K}^{+}$-ATPase with simultaneous transportation of sodium against electrochemical gradient out of cells into intercellular space followed by absorption into blood through fibrocytes in spiral ligament. Other kin$\mathrm{d}(\mathrm{s})$ of channel responsible for sodium transportation in the stria vascularis of guinea pig may exist. Another possibility is that post-transcriptional regulatory mechanisms may inhibit translation of mRNA of $\mathrm{ENaC}$ into protein so that the protein level is too low to be detected by immunohistochemistry. Further studies are needed to verify these possibilities.

\section{Conclusion}

Alpha-, $\beta$-, and $\gamma$-ENaC, SGK1 and Nedd 4 isoforms are expressed in the guinea pig cochlea with differential patterns. Most of the regions are closely related to the regulation of endolymph homeostasis. $\mathrm{ENaC}$, SGK1 and Nedd4 in the cochlea may mediate passive entry of sodium into cells just as they do in other epithelia present in kidney, lung and colon. Absence of these proteins in the stria vascularis of guinea pig suggests that endolymph homeostasis may be subjected to species-specific mechanisms.

\section{Acknowledgements}

The authors thank Prof. Pascal Barbry for kindly providing the polyclonal antibodies against $\alpha-, \beta$-, and $\gamma$-ENaC, Prof. Nicola Perrotti for antibody against SGK1, and Prof. Olivier Staub for antibodies against Nedd4-1/2 and Nedd4-2. We also thank Mrs. Jin-Qing Yang and Mrs. Juan Du for their invaluable assistance with the histological techniques.

\section{References}

1. Bosher SK, Warren RL. A study of the electrochemistry and osmotic relationships of the cochlear fluids in the neonatal rat at the time of the development of the endocochlear potential. J Physiol. 1971;212:739-761.

2. Salt AN, Melichar I, Thalmann R. Mechanisms of endocochlear potential generation by stria vascularis. Laryngoscope. 1987:97:984-991.

3. Wangemann P. Comparison of ion transport mechanisms between vestibular dark cells and strial marginal cells. Hear Res. 1995;90:149-157.

4. Paparella MM, Djalilian HR. Etiology, pathophysiology of symptoms, and pathogenesis of Meniere's disease. Otolaryngol Clin North Am. 2002;35:529-545.
5. Crouch JJ, Sakaguchi N, Lytle C et al. Immunohistochemical localization of the Na-K-Cl co-transporter (NKCC1) in the gerbil inner ear. J Histochem Cytochem. 1997;45:773-778.

6. ten Cate WJ, Curtis LM, Rarey KE. Na,K-ATPase alpha and beta subunit isoform distribution in the rat cochlear and vestibular tissues. Hear Res. 1994;75:151-160.

7. Kamynina E, Staub O. Concerted action of ENaC, Nedd4-2, and SGK1 in transepithelial $\mathrm{Na}+$ transport. Am J Physiol Renal Physiol. 2002;283:F377-F387.

8. Zhong SX, Liu ZH. Immunohistochemical localization of the epithelial sodium channel in the rat inner ear. Hear Res. 2004;193:1-8.

9. Zhong SX, Liu ZH. Expression patterns of Nedd4 isoforms and SGK1 in the rat cochlea. Acta Otolaryngol. 2009;128:935939.

10. Couloigner V, Fay M, Djelidi S et al. Location and function of the epithelial Na channel in the cochlea. Am J Physiol Renal Physiol. 2001;280:F214-F222.

11. Grunder S, Muller A, Ruppersberg JP. Developmental and cellular expression patterns of epithelial sodium channel $\alpha$, $\beta$, and $\gamma$ subunits in the inner ear of the rat. Eur J Neurosci. 2001;13:641-648.

12. Castellani RJ, Gupta Y, Sheng B et al. A novel origin for granulovacuolar degeneration in aging and Alzheimer's disease: parallels to stress granules. Lab Invest. 2011;91:1777-1786.

13. Kong $\mathrm{Y}$, Jing $\mathrm{G}$, Yan $\mathrm{Z}$ et al. Cloning and characterization of Prisilkin-39, a novel matrix protein serving a dual role in the prismatic layer formation from the oyster Pinctada fucata. J Biol Chem. 2009;284:10841-10854.

14. Barbry P, Hofman P. Molecular biology of $\mathrm{Na}^{+}$absorption. Am J Physiol. 1997; 273:G571-G585.

15. Faletti CJ, Perrotti N, Taylor SI et al. SGK: an essential convergence point for peptide and steroid hormone regulation of ENaC-mediated $\mathrm{Na}^{+}$transport. Am J Physiol Cell Physiol. 2002;282:C494-C500.

16. Staub $\mathrm{O}$, Yeger $\mathrm{H}$, Plant $\mathrm{P}$ et al. Immunolocalization of the ubiquitin-protein ligase Nedd4 in tissues expressing the epithelial $\mathrm{Na}^{+}$channel (ENaC). Am J Physiol. 1997;272:C1871-C1880.

17. Hager H, Kwon TH, Vinnikova AK et al. Immunocytochemical and immunoelectron microscopic localization of alpha-, beta-, and gamma-ENaC in rat kidney. Am J Physiol Renal Physiol. 2001;280:F1093-F1106.

18. Loffing J, Zecevic M, Feraille E et al. Aldosterone induces rapid apical translocation of $\mathrm{ENaC}$ in early portion of renal collecting system: possible role of SGK. Am J Physiol Renal Physiol. 2001;280:F675-F682.

19. Alvarez de la Rosa D, Canessa CM, Fyfe GK et al. Structure and regulation of amiloride-sensitive sodium channels. Annu Rev Physiol. 2000;62:573-594.

20. Palmer LG. Epithelial Na Channels. Why All the Subunits? J Gen Physiol. 1997;109:675-676.

21. Schild L. The epithelial sodium channel and the control of sodium balance. Biochim Biophys Acta. 2010;802:1159-1165 .

22. Waldmann R, Champigny G, Bassilana F et al. Molecular cloning and functional expression of a novel amiloride-sensitive $\mathrm{Na}^{+}$channel. J Biol Chem. 1995;270:27411-27414.

23. Wangemann $\mathrm{P} . \mathrm{K}^{+}$cycling and the endocochlear potential. Hear Res. 2002;165:1-9. 